\title{
THE ESTIMATION OF HERITABILITY AND DEGREE OF DOMINANCE FROM A DIALLEL CROSS
}

\author{
D. G. PEDERSON \\ Biometry Section, Faculty of Agriculture, University of Sydney, \\ Sydney, New South Wales, Australia
}

Received 12.xi.70

\section{INTRODUCTION}

Estimates of genetic and environmental variance are often used to determine the potential of a breeding population, and among the many crossing designs available (e.g. see Cockerham, 1963) the diallel cross is in common usage. It is the purpose of this paper to consider how the diallel analysis may be used to obtain efficient estimates of two parameters, namely the heritability and the degree of dominance. The only crossing design to be considered is that designated "Method 4" by Griffing (1956), in which no selfed material or reciprocal crosses are used, and a completely random model, in the usual statistical sense, will be assumed throughout.

With the information available at present it is necessary to make an arbitrary decision at three stages of the diallel cross procedure. The number of parents is the first of these decisions, after which a choice must be made as to the number of individuals to be grown per cross and the number of replicates in the experimental design. The problem of the number of parents has been considered by Hayman (1960), with the conclusion that a diallel cross of 10 parents would supply useful estimates of the genetic components of variance within a population. Cockerham (1963) considers that this number is generally too conservative. However, in a discussion of the partial diallel cross Kempthorne and Curnow (1961) pointed out that to minimise the variance of two estimates is not necessarily to minimise the variance of their ratio, and the results of Hayman must be viewed in this light when the ratios of genetic variances, such as the heritability and the degree of dominance, are of interest.

It is therefore the aim of this paper to suggest suitable values for the three controllable variables inherent in the diallel cross. Results have been obtained by way of a simulation procedure carried out on an electronic computer.

\section{Estimation OF SAMPLING Distributions}

The experimental material for diallel method 4 consists of the $\frac{1}{2} p(p-1)$ $F_{1}$ hybrids between $p$ randomly chosen parents. The analysis of variance for $r$ replicates, with $n$ individuals per family, is given in table 1. A genetic model of non-interacting loci is assumed and the general combining ability (g.c.a.) and specific combining ability (s.c.a.) variances (Griffing, 1956) have been replaced by functions of the additive genetic variance $\left(\sigma_{A}^{2}\right)$, the dominance variance $\left(\sigma_{D}^{2}\right)$, and $F$, the degree of inbreeding of the randomly chosen parents relative to the population of interest. The appropriate functions were obtained from Kempthorne and Curnow (1961). The 
inbreeding parameter refers to the parents of the diallel, while the genetic variances are parameters of the population for which estimates are required.

It has been assumed that each full-sib family is grown as a discrete unit within a replicate so that the variance $\sigma_{P}^{2}$ is interpreted as experimental error, or the plot-to-plot environmental variance in the case of plant material. The environmental variance exhibited by individuals within a

TABLE 1

Expected mean squares for diallel method 4

Source
Families $\left\{\begin{array}{lll}\text { g.c.a. } & p-1 & \multicolumn{1}{c}{\text { d.f. }} \\ \text { s.c.a. } & \frac{1}{2} p(p-3) & \sigma_{E}^{2}+n \sigma_{P}^{2}+\frac{1}{4} n r(1+F)^{2} \sigma_{D}^{2}+\frac{1}{4} n r(p-2)(1+F) \sigma_{A}^{2} \\ \text { Experimental error } & \frac{1}{2}(r-1)(p-2)(p+1) & \sigma_{E}^{2}+n \sigma_{P}^{2}+\frac{1}{4} n r(1+F)^{2} \sigma_{D}^{2} \\ \text { Sampling error } & \frac{1}{2} r p(p-1)(n-1) & \sigma_{E}^{2}\end{array}\right.$

family is designated $\sigma_{W}^{2}$, and the total variation between such individuals is considered to be the sum of $\sigma_{W}^{2}$ and the genetic variance between individuals, namely the total genetic variance minus the covariance of full-sibs.

i.e.

$$
\begin{aligned}
\sigma_{E}^{2} & =\sigma_{W}^{2}+\sigma_{G}^{2}-\operatorname{cov} \text { (F.S.) } \\
& =\sigma_{W}^{2}+\frac{1}{2}(1-F) \sigma_{A}^{2}+\frac{1}{4}(3+F)(1-F) \sigma_{D}^{2} .
\end{aligned}
$$

Competition within plots is therefore assumed to be absent.

From an analysis of this type an estimate may be obtained for the heritability of an individual, defined as

$$
h_{\text {individual }}^{2}=\frac{\sigma_{A}^{2}}{\sigma_{A}^{2}+\sigma_{D}^{2}+\sigma_{W}^{2}} .
$$

The estimate, which is relevant to selection within groups of size $n$, is obtained as a function of the mean squares in the analysis. Since the variances of the mean squares are known and they are uncorrelated, the approximate formula for the variance of a ratio

$$
\operatorname{var}(X / Y)=\frac{1}{\Upsilon^{2}}\left[\operatorname{var}(X)-2 \frac{X}{\Upsilon} \operatorname{cov}(X, Y)+\left(\frac{X}{\Upsilon}\right)^{2} \operatorname{var}(\Upsilon)\right]
$$

may be used to derive the sampling variance of the heritability. This being so, it should be possible to suggest values of $p, r$ and $n$ which mininise the sampling variance for particular values of $F$ and the population variances. However, the expression (1) was found to be not sufficiently accurate when there were few degrees of freedom in the analysis and a less direct approach to the problem was therefore preferred.

An essential part of the process was the generation of random values of the standard normal variate (SNV) and of the chi-square variate with one degree of freedom $\left(\chi_{1}^{2}\right)$. Some preliminary work was necessary so that this could be done. 
The first step was to determine, from the tables of Pearson (1930), the abscissa values which divide the standard normal distribution into 1000 parts of equal area. In general, the expected value within a class bounded by $a$ and $b$ where $b>a$ is given by,

$$
\begin{aligned}
& \frac{1}{\sqrt{2 \pi}} \int_{a}^{b} x \cdot e^{-\frac{1}{2} x^{4}} \cdot d x / \frac{1}{\sqrt{2 \pi}} \int_{a}^{b} e^{-\frac{1}{2} x^{4}} \cdot d x \\
& =\quad\left(z_{a}-z_{b}\right) / 0 \cdot 001
\end{aligned}
$$

where $z_{a}$ and $z_{b}$ are the ordinates of the distribution at $a$ and $b$ respectively. This result was used to calculate the expected value within each of the 1000 classes. Subsequently, the procedure followed in generating a random SNV-value was to first obtain a uniformly distributed random digit between 1 and 1000 , say the digit $M$, and then to use the expected value within the $M$ th region of the standard normal distribution. A total of 100,000 values were generated as a check and were found to have a mean of 0.0002 and a variance of 0.9986 , compared with the expected values of 0 and 1 respectively.

If $a$ and $b$ enclose 0.001 of the standard normal distribution, then $a^{2}$ and $b^{2}$ enclose 0.002 of the chi-square distribution with one degree of freedom, so that the same class limits as previously determined were used to divide the chi-square distribution into 500 parts of equal area. The expected value within the region $\left(a^{2}, b^{2}\right)$ is given by

$$
1+\left(a z_{a}-b z_{b}\right) / 0 \cdot 001
$$

$z_{a}$ and $z_{b}$ being as previously defined. The 500 expected values were calculated, after which the generation of a random digit between 1 and 500 was sufficient to obtain an approximately random value of $\chi_{1}^{2}$. A total of 100,000 such values were found to have a mean of 0.9987 and a variance of 1.9673 , the latter being somewhat less than the expected value of 2 due to the approximation of considering a finite number of regions within the distribution.

When a random value was required for a chi-square variate with $\mathcal{N}$ degrees of freedom, $\mathcal{N}$ random values of $\chi_{1}^{2}$ were summed. In some cases, particularly for large $\mathcal{N}$, use was made of the approximation

$$
\chi_{N}^{2}=\frac{1}{2}\left(\mathrm{SNV}+(2 \mathcal{N}-1)^{\frac{1}{2}}\right)^{2}
$$

and a random value of the SNV gave a random value for $\chi_{N}^{2}$.

Consider now a population distributed normally with variance $\sigma^{2}$. For a random sample of $m$ observations the sum of squares of deviations from the sample mean is distributed as $\sigma^{2} \chi_{m-1}^{2}$, and the mean square is therefore distributed as $\sigma^{2} \chi_{m-1}^{2} /(m-1)$. Applying this to the present situation, if successive samples of $p$ parents are chosen at random and a diallel analysis is carried out for each, the g.c.a. mean square is distributed as

$$
\left[\sigma_{E}^{2}+n \sigma_{P}^{2}+\frac{1}{4} n r(1+F)^{2} \sigma_{D}^{2}+\frac{1}{4} n r(p-2)(1+F) \sigma_{A}^{2}\right] \chi_{p-1}^{2} /(p-1) .
$$

The remaining three mean squares are similarly distributed.

Provided the expectations of the mean squares are known, a simulated diallel analysis may therefore be carried out. A randomly chosen value of 
$\chi_{p-1}^{2}$ is multiplied by the expectation of the g.c.a. mean square and divided by $(p-1)$ to give an " observed" g.c.a. mean square, and similar processes give a value for each of the other three mean squares. An estimate of heritability is thus obtained and from repetitions of the procedure the sampling distribution of estimates is built up. In the present case 500 estimates were used to determine a sampling distribution, and this was done for four hypothetical populations with variance parameters

$\begin{array}{crrr}\text { Population } & \sigma_{A}^{2} & \sigma_{D}^{2} & \sigma_{W}^{2} \\ 1 & 21 & 0 & 84 \\ 2 & 24 & 12 & 84 \\ 3 & 126 & 0 & 84 \\ 4 & 504 & 252 & 84\end{array}$

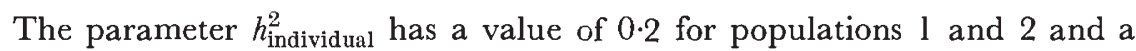
value of 0.6 for the remaining two populations. The experimental error variance was assumed to be zero throughout, an assumption which will be discussed briefly in a later section, and $F$ was put equal to both 0 and 1 . Since the aim was to find for each population the combination of $p, r$ and $n$ which minimises the sampling variance of $h_{\text {individual the following values }}^{2}$ were tested:

$$
\begin{aligned}
& p=4,6,8,10,12,14,16,18,20 \\
& r=2,3,5 \\
& n=2,3,5,10 .
\end{aligned}
$$

From table 1 it is seen that once each of the above parameters and variables has been specified the expectations of the mean squares are known and the simulation procedure may be carried out.

In a practical situation a number of heritabilities may be calculated from the estimates of variance for a particular population. It would therefore be unfortunate if the combination of values which minimise the variance of $h_{\text {individual }}^{2}$ were unsuitable for estimating, say, the heritability of full-sib families $\left(h_{\text {family }}^{2}\right)$, a parameter commonly of interest. For this reason the sampling variance of $h_{\text {family }}^{2}$ was also estimated using the identity

$$
h_{\text {family }}^{2}=\frac{\frac{1}{2} \sigma_{A}^{2}(1+1 / f)}{\left(\sigma_{E}^{2} / f\right)+\sigma_{P}^{2}+\operatorname{cov}(\text { F.S. })},
$$

where $f$ is the proposed number of individuals per selected family. To reduce the dimensions of the problem only the case of $F=0$ was considered since $f$ is an additional variable in the system and this was put equal to 2 and 5 .

The other parameter which has been investigated is the degree of dominance, defined as

$$
d=2 \sigma_{D}^{2} / \sigma_{A}^{2}
$$

and which therefore has a value of 0 for populations 1 and 3 , and 1 for populations 2 and 4 . This is the square of the more common definition of the degree of dominance parameter (Comstock and Robinson, 1948) but the sample estimate was often negative, with an undefined square root, and it was therefore necessary to define $d$ in the manner shown. 


\section{SAMPLING Distributions OF HERITABILITY ESTIMATES}

\section{(i) Heritability of individuals}

The distribution of $\hat{h}_{\text {individual, the estimate of individual heritability, was }}^{2}$ generally positively skewed and was found to have a mean less than the true value. A subset of the results for $F=0$ are given in table 2, showing that the negative bias is from 2 per cent. to 7 per cent. of the true value for an 8-parent diallel and decreases to less than $2 \cdot 5$ per cent. for a 20 -parent diallel. The bias is very little dependent on the value of $r$ or $n$. For $F=1$ it is sufficient

TABle 2

Mean of sampling distribution of $h_{\text {individual }}^{2}\left(\times 10^{3}\right)$.

\begin{tabular}{|c|c|c|c|c|c|c|c|c|c|c|c|}
\hline \multirow[b]{2}{*}{ Population } & \multirow[b]{2}{*}{$r$} & \multirow[b]{2}{*}{$n$} & \multicolumn{9}{|c|}{ Number of parents $(p)$} \\
\hline & & & 4 & 6 & 8 & 10 & 12 & 14 & 16 & 18 & 20 \\
\hline \multirow[t]{2}{*}{1} & 2 & $\begin{array}{r}2 \\
10\end{array}$ & $\begin{array}{l}136 \\
197\end{array}$ & $\begin{array}{l}190 \\
194\end{array}$ & $\begin{array}{l}191 \\
194\end{array}$ & $\begin{array}{l}195 \\
195\end{array}$ & $\begin{array}{l}193 \\
194\end{array}$ & $\begin{array}{l}193 \\
194\end{array}$ & $\begin{array}{l}194 \\
194\end{array}$ & $\begin{array}{l}194 \\
195\end{array}$ & $\begin{array}{l}197 \\
197\end{array}$ \\
\hline & 5 & $\begin{array}{r}2 \\
10\end{array}$ & $\begin{array}{l}181 \\
198\end{array}$ & $\begin{array}{l}193 \\
195\end{array}$ & $\begin{array}{l}194 \\
195\end{array}$ & $\begin{array}{l}195 \\
195\end{array}$ & $\begin{array}{l}194 \\
194\end{array}$ & $\begin{array}{l}193 \\
194\end{array}$ & $\begin{array}{l}194 \\
195\end{array}$ & $\begin{array}{l}194 \\
195\end{array}$ & $\begin{array}{l}197 \\
197\end{array}$ \\
\hline \multirow[t]{2}{*}{2} & 2 & $\begin{array}{r}2 \\
10\end{array}$ & $\begin{array}{l}142 \\
191\end{array}$ & $\begin{array}{l}187 \\
192\end{array}$ & $\begin{array}{l}190 \\
194\end{array}$ & $\begin{array}{l}195 \\
194\end{array}$ & $\begin{array}{l}193 \\
193\end{array}$ & $\begin{array}{l}193 \\
193\end{array}$ & $\begin{array}{l}193 \\
194\end{array}$ & $\begin{array}{l}194 \\
194\end{array}$ & $\begin{array}{l}196 \\
197\end{array}$ \\
\hline & 5 & $\begin{array}{r}2 \\
10\end{array}$ & $\begin{array}{l}171 \\
195\end{array}$ & $\begin{array}{l}191 \\
193\end{array}$ & $\begin{array}{l}193 \\
194\end{array}$ & $\begin{array}{l}194 \\
194\end{array}$ & $\begin{array}{l}193 \\
194\end{array}$ & $\begin{array}{l}193 \\
193\end{array}$ & $\begin{array}{l}194 \\
194\end{array}$ & $\begin{array}{l}194 \\
195\end{array}$ & $\begin{array}{l}197 \\
197\end{array}$ \\
\hline \multirow[t]{2}{*}{3} & 2 & $\begin{array}{r}2 \\
10\end{array}$ & $\overline{539}$ & $\begin{array}{l}556 \\
557\end{array}$ & $\begin{array}{l}562 \\
565\end{array}$ & $\begin{array}{l}571 \\
569\end{array}$ & $\begin{array}{l}570 \\
571\end{array}$ & $\begin{array}{l}574 \\
573\end{array}$ & $\begin{array}{l}577 \\
577\end{array}$ & $\begin{array}{l}577 \\
578\end{array}$ & $\begin{array}{l}584 \\
584\end{array}$ \\
\hline & 5 & $\begin{array}{r}2 \\
10\end{array}$ & $\begin{array}{l}524 \\
544\end{array}$ & $\begin{array}{l}558 \\
558\end{array}$ & $\begin{array}{l}564 \\
567\end{array}$ & $\begin{array}{l}569 \\
570\end{array}$ & $\begin{array}{l}570 \\
571\end{array}$ & $\begin{array}{l}573 \\
573\end{array}$ & $\begin{array}{l}577 \\
577\end{array}$ & $\begin{array}{l}578 \\
578\end{array}$ & $\begin{array}{l}584 \\
585\end{array}$ \\
\hline \multirow[t]{2}{*}{4} & 2 & $\begin{array}{r}2 \\
10\end{array}$ & $\begin{array}{l}309 \\
500\end{array}$ & $\begin{array}{l}542 \\
545\end{array}$ & $\begin{array}{l}556 \\
560\end{array}$ & $\begin{array}{l}567 \\
566\end{array}$ & $\begin{array}{l}568 \\
568\end{array}$ & $\begin{array}{l}572 \\
571\end{array}$ & $\begin{array}{l}575 \\
575\end{array}$ & $\begin{array}{l}576 \\
577\end{array}$ & $\begin{array}{l}583 \\
584\end{array}$ \\
\hline & 5 & $\begin{array}{r}2 \\
10\end{array}$ & $\begin{array}{l}471 \\
509\end{array}$ & $\begin{array}{l}544 \\
545\end{array}$ & $\begin{array}{l}559 \\
561\end{array}$ & $\begin{array}{l}566 \\
566\end{array}$ & $\begin{array}{l}568 \\
569\end{array}$ & $\begin{array}{l}571 \\
571\end{array}$ & $\begin{array}{l}575 \\
575\end{array}$ & $\begin{array}{l}577 \\
577\end{array}$ & $\begin{array}{l}584 \\
584\end{array}$ \\
\hline
\end{tabular}

to state that the bias follows the same pattern but is marginally greater overall.

The other distribution characteristic of interest is the sampling variance, the aim being to minimise this statistic. However, it has been thought preferable to consider the inverse of the sampling variance, the quantity generally referred to as the "amount of information" or the "invariance"

$$
\text { viz. } I=1 / \text { variance }\left(\hat{h}^{2}\right) \text {. }
$$

The problem of minimisation therefore becomes one of maximising $I$, but the solution is trivial since an increase in any one of $p, r$, or $n$ will bring about an increase in the total amount of information. A further modification was therefore necessary and the values which will be presented are for the quantity $i$, defined as the amount of information per individual in the diallel cross.

$$
\text { i.e. } \quad i=I /\left[\frac{1}{2} p(p-1) r n\right] .
$$

The most efficient system is defined as that which maximises $i$.

The values of $i$ for populations 1 and 2 are given in tables $3 a$ and $3 b$. 
TABLE $3 a$

Amount of information per individual $\left(\times 10^{3}\right)$ for population 1

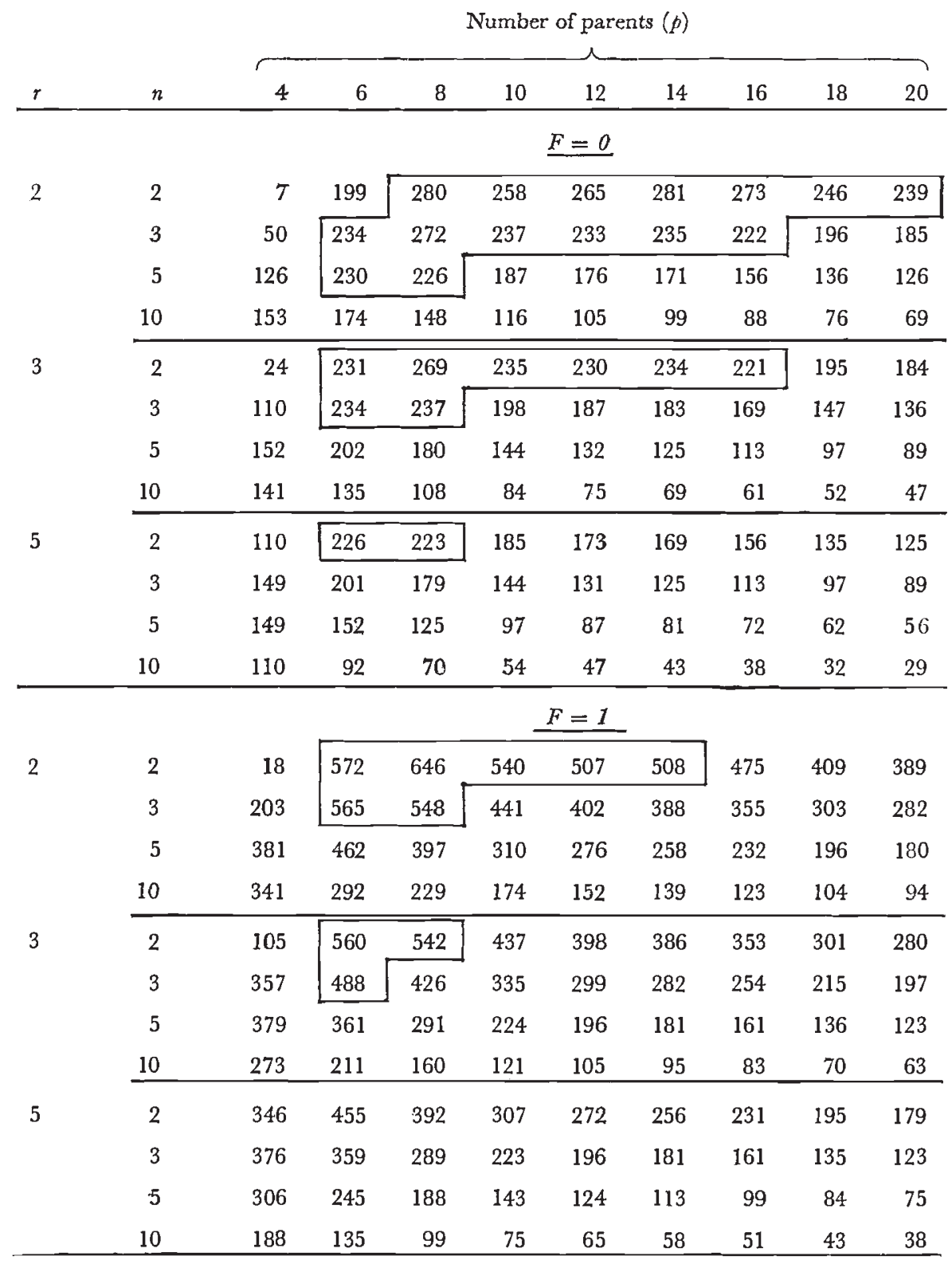


TABLE $3 b$

Amount of information per individual $\left(\times 10^{3}\right)$ for population 2

Number of parents $(p)$

\begin{tabular}{|c|c|c|c|c|c|c|c|c|c|c|}
\hline$r$ & $n$ & 4 & 6 & 8 & 10 & 12 & 14 & 16 & 18 & 20 \\
\hline \multirow{5}{*}{2} & & & & & & $F=0$ & & & & \\
\hline & 2 & 6 & 184 & 261 & 245 & 253 & 269 & 263 & 238 & 231 \\
\hline & 3 & 39 & 207 & 248 & 221 & 219 & 223 & 212 & 188 & 178 \\
\hline & 5 & 92 & 195 & 201 & 171 & 163 & 160 & 148 & 129 & 120 \\
\hline & 10 & 101 & 142 & 129 & 105 & 97 & 92 & 83 & 72 & 66 \\
\hline \multirow[t]{3}{*}{3} & 2 & 18 & 205 & 245 & 219 & 217 & 222 & 211 & 187 & 177 \\
\hline & 3 & 81 & 200 & 211 & 182 & 174 & 172 & 160 & 140 & 130 \\
\hline & 5 & 104 & 167 & 158 & 131 & 122 & 117 & 106 & 92 & 85 \\
\hline \multirow{5}{*}{$j$} & 10 & 89 & 109 & 94 & 75 & 69 & 64 & 57 & 50 & 45 \\
\hline & 2 & 78 & 192 & 199 & 169 & 161 & 159 & 147 & 128 & 119 \\
\hline & 3 & 102 & 166 & 157 & 130 & 121 & 117 & 106 & 92 & 85 \\
\hline & 5 & 96 & 124 & 108 & 88 & 80 & 76 & 68 & 59 & 53 \\
\hline & 10 & 67 & 73 & 60 & 48 & 43 & 40 & 36 & 31 & 28 \\
\hline
\end{tabular}

\begin{tabular}{|c|c|c|c|c|c|c|c|c|c|c|}
\hline \multirow[b]{2}{*}{2} & \multirow[b]{2}{*}{2} & \multirow[b]{2}{*}{0} & \multicolumn{6}{|c|}{$F=1$} & \multirow[b]{2}{*}{380} & \multirow[b]{2}{*}{361} \\
\hline & & & 454 & 538 & 477 & 458 & 459 & 434 & & \\
\hline & 3 & 82 & 408 & 434 & 374 & 352 & 343 & 318 & 276 & 258 \\
\hline & 5 & 144 & 310 & 303 & 255 & 236 & 224 & 205 & 177 & 163 \\
\hline & 10 & 118 & 186 & 169 & 141 & 128 & 119 & 108 & 93 & 84 \\
\hline \multirow[t]{4}{*}{3} & 2 & 39 & 405 & 431 & 372 & 349 & 341 & 318 & 274 & 257 \\
\hline & 3 & 132 & 331 & 327 & 278 & 257 & 245 & 225 & 194 & 179 \\
\hline & 5 & 134 & 233 & 217 & 182 & 166 & 156 & 141 & 121 & 111 \\
\hline & 10 & 91 & 132 & 117 & 97 & 88 & 81 & 73 & 63 & 57 \\
\hline \multirow[t]{4}{*}{5} & 2 & 119 & 307 & 300 & 254 & 233 & 223 & 205 & 176 & 162 \\
\hline & 3 & 131 & 233 & 217 & 181 & 165 & 156 & 141 & 121 & 111 \\
\hline & 5 & 103 & 154 & 138 & 115 & 104 & 97 & 87 & 75 & 68 \\
\hline & 10 & 61 & 83 & 72 & 60 & 54 & 50 & 44 & 38 & 34 \\
\hline
\end{tabular}




\section{TABLE 4}

Heritability of individuals; regions of maximum amount of information for populations 3 and 4

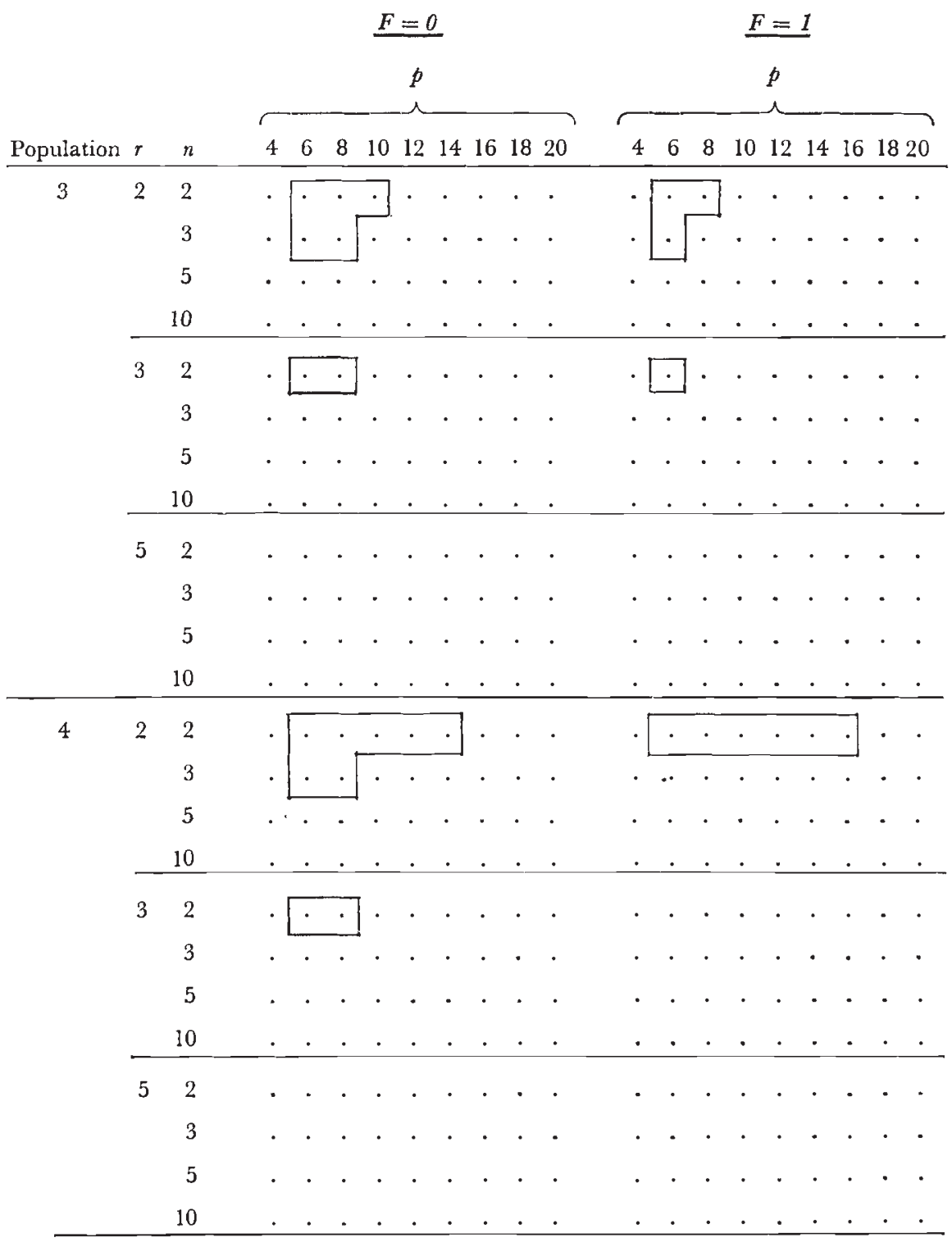


The " boxes" enclose values which are within 25 per cent. of the maximum value, thus giving a visual indication of the preferred values of $p, r$ and $n$. The two populations differ in the magnitude of the dominance variance but the same conclusion is drawn for each, namely that $i$ is maximised by using 2 or 3 replicates with 2 or 3 individuals per family. The optimum number of parents is approximately 8 , and there is no significant dependence on the degree of inbreeding of the parents.

Since the main interest is in the region of maximisation of $i$, the results for the remaining two populations are summarised qualitatively in table 4 . As in table 3 the boxes enclose values which deviate from the maximum by less than 25 per cent. of its value. Although these regions are more restricted than for populations 1 and 2 the general conclusion is unchanged, namely that for efficient estimation $r$ and $n$ should be small and $p$ should be approximately 8 .

As stated previously, the simplifying assumption has been made that $\sigma_{P}^{2}$, the component of variance between plots, is zero. In fact a relationship of the type

$$
\text { variance of plot means }=\frac{1}{n^{b}} \text { (variance of individuals) }
$$

was shown by Smith (1938) to have general validity for plant material. Estimates of $b$ were obtained for various crops and these ranged from $0 \cdot 16$ to $0 \cdot 80$, with an average of about $0 \cdot 5$.

In terms of the present notation the relationship is

$$
\begin{aligned}
\frac{\sigma_{E}^{2}}{n}+\sigma_{P}^{2} & =\frac{\sigma_{E}^{2}}{n^{b}} \\
\sigma_{P}^{2} & =\sigma_{E}^{2}\left[\frac{1}{n^{b}}-\frac{1}{n}\right] .
\end{aligned}
$$

i.e.

For $b=0.5, \sigma_{E}^{2}=84$, and $n=2$ we calculate $\sigma_{P}^{2}=17 \cdot 4$, and for $n=10$ the result is $\sigma_{P}^{2}=18 \cdot 2$. The simulation procedure was therefore repeated for populations 1 and 2 but with $\sigma_{P}^{2}=20$. The results are shown in table 5 and there is no real deviation from the corresponding results for $\sigma_{P}^{2}=0$, suggesting that the conclusions of this study will not depend to any great extent on the assumption of zero plot effect.

\section{(ii) Heritability of full-sib families}

The estimator for familial heritability was found to be negatively biassed to the extent of approximately 20 per cent. for a 4-parent diallel through to 3 per cent. for a 20-parent diallel.

Efficiency was again measured by $i$, the amount of information per individual in the diallel cross, and the results are presented in tables $6 a$ and $6 b$.

For $f=2$ it is concluded that 2 replicates should be used, with 2 or 3 individuals per family and any number from 6 through to 16 parents. A low number of parents in combination with small $n$ is unsuitable when $f=5$, and it seems that $n$ should approximately equal the projected $f$ if a zero denominator for the heritability estimate is to be avoided with any degree of certainty. 
TABle 5

Heritability of individuals; regions of maximum amount of information when plot variance is non-zero

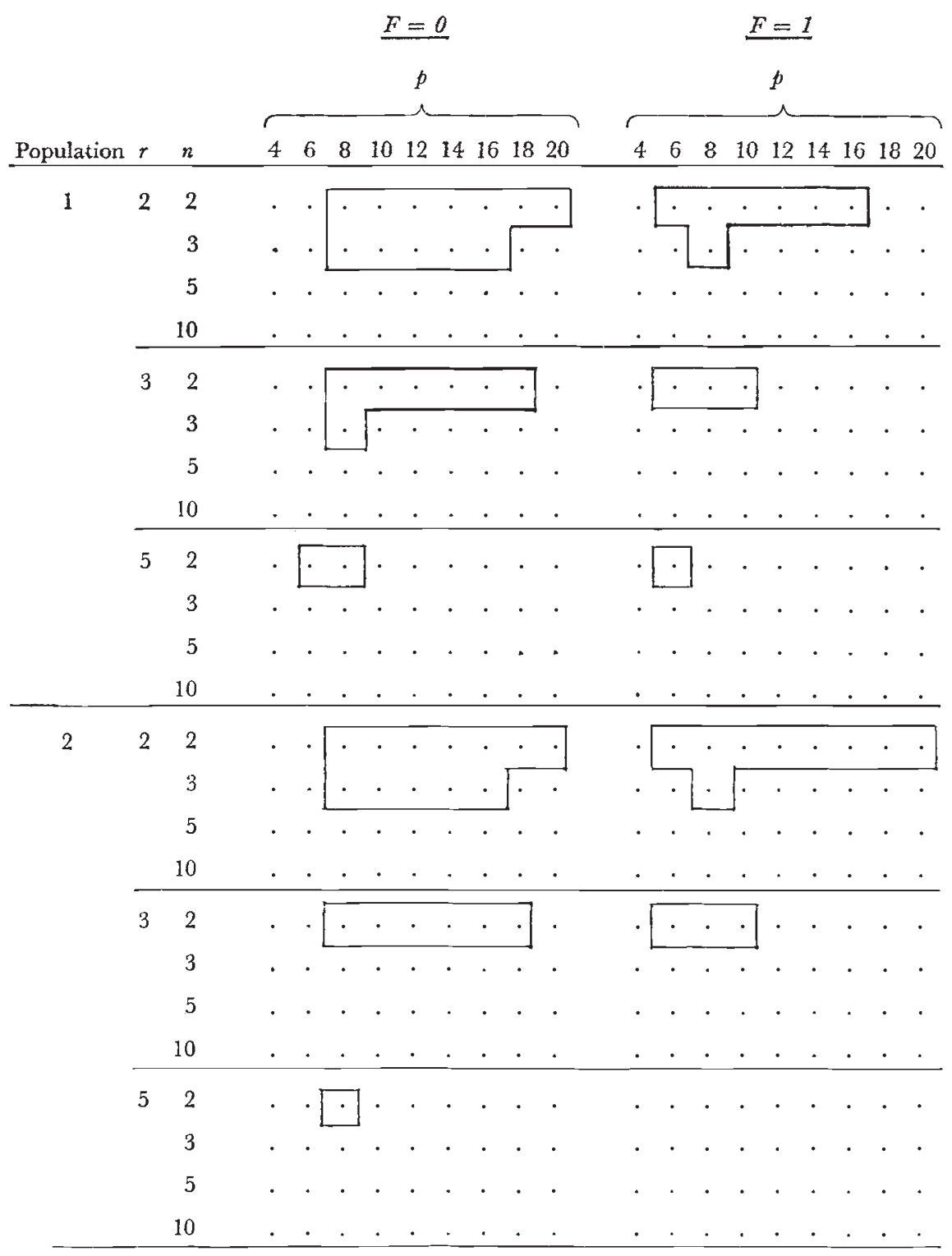


TABLE $6 a$

Heritability of full-sib families; regions of maximum amount of information for populations 1 and 2

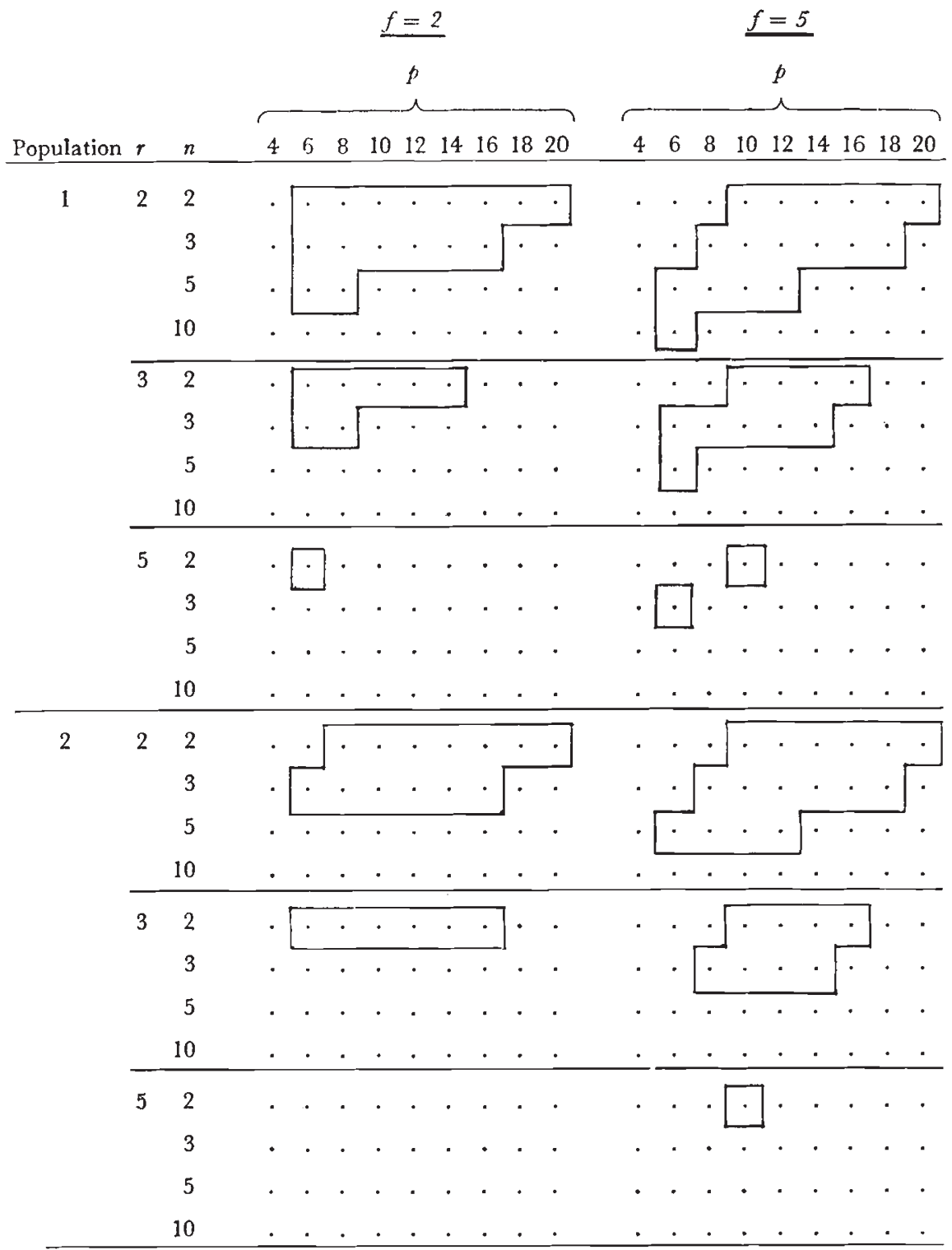




\section{TABLE $6 b$}

Heritability of full-sib families; regions of maximum amount of information for populations 3 and 4

\begin{tabular}{|c|c|c|c|c|c|c|c|c|c|c|c|c|c|c|c|c|c|c|c|c|}
\hline \multirow[b]{3}{*}{ Population } & \multirow[b]{3}{*}{$r$} & & \multicolumn{9}{|c|}{$f=2$} & \multicolumn{9}{|c|}{$f=5$} \\
\hline & & & \multicolumn{9}{|c|}{$p$} & \multicolumn{9}{|c|}{$p$} \\
\hline & & $n$ & 4 & 6 & 8 & 10 & 12 & 14 & 16 & 18 & 20 & 4 & 6 & 8 & 10 & 12 & 14 & 16 & 18 & 20 \\
\hline 3 & 2 & 2 & . & . & . & . & - & . & . & . & . & . & & . & . & . & - & . & . & . \\
\hline & & 3 & . & . & . & $\cdot$ & . & $\cdot$ & · & . & . & . & . & $\cdot$ & - & $\cdot$ & . & . & & . \\
\hline & & 5 & . & $\cdot$ & $\cdot$ & . & · & . & $\cdot$ & . & . & . & . & . & $\cdot$ & $\cdot$ & $\cdot$ & $\cdot$ & $\cdot$ & $\cdot$ \\
\hline & & 10 & $\cdot$ & . & . & . & . & . & - & . & $\cdot$ & $\cdot$ & . & $\cdot$ & . & . & $\cdot$ & $\cdot$ & $\cdot$ & $\cdot$ \\
\hline & 3 & 2 & . & . & . & . & . & . & . & - & . & . & & $\overline{.}$ & . & $\cdot$ & $\cdot$ & $\cdot$ & $\cdot$ & - \\
\hline & & 3 & . & . & . & . & $\cdot$ & . & $\cdot$ & $\cdot$ & $\cdot$ & · & $\cdot$ & - & $\cdot$ & . & - & $\cdot$ & $\cdot$ & $\cdot$ \\
\hline & & 5 & . & . & . & . & . & $\cdot$ & . & . & . & $\cdot$ & . & . & . & $\cdot$ & $\cdot$ & $\cdot$ & $\cdot$ & - \\
\hline & & 10 & . & . & . & . & . & . & . &. & $\cdot$ & . & . &. & . & $\cdot$ & . & $\cdot$ & $\cdot$ & $\therefore$ \\
\hline & 5 & 2 & . & . & . & . & • & . & . & . & . & . & . & . & . & · & • & . & $\cdot$ & . \\
\hline & & 3 & . & - & $\cdot$ & - & . & . & $\cdot$ & . & - & - & . & $\cdot$ & • & . & • & . & . & . \\
\hline & & 5 & . & . & • & . & . & . & . & . & . & . & . & . & • & . & . & $\cdot$ & $\cdot$ & $\cdot$ \\
\hline & & 10 & . & . & . & . & . & . & . & . & . & . & . & . & . & . & . & $\cdot$ & . & . \\
\hline 4 & 2 & 2 & . & . & . & . & . & . & . & $\cdot$ & & . & & . & . & . & . & $\cdot$ & $\cdot$ & $\cdot$ \\
\hline & & 3 & • & . & . & . & . & . & . & $\cdot$ & • & . & & . & $\cdot$ & . & . & $\cdot$ & $\cdot$ & $\cdot$ \\
\hline & & 5 & . & . & $\cdot$ & . & . & . & . & . & . & . & & • & $\cdot$ & $\cdot$ & $\cdot$ & $\cdot$ & $\cdot$ & $\cdot$ \\
\hline & & 10 & $\therefore$ & . & . & . & . & . & . & . & . & • & . & . & . & - & . & • & . & . \\
\hline & 3 & 2 & . & . & . & . & . & . & . & . & . & $\cdot$ & & . & . & . & . & . & . & . \\
\hline & & 3 & . & . & . & - & . & . & . & . & . & . & & . & $\cdot$ & $\cdot$ & · & $\cdot$ & . & . \\
\hline & & 5 & . & . & . & . & . & • & . & . & $\cdot$ & - & . & . & . & . & $\cdot$ & . & $\cdot$ & • \\
\hline & & 10 & . & . & . & . & . & . & . & . & . & $\cdot$ & . & . & . & . & • & . & $\cdot$ & . \\
\hline & 5 & 2 & . & . & . & . & . & . & . & $\cdot$ & . & . & & . & $\cdot$ & . & . & . & . & . \\
\hline & & 3 & . & . & . & . & . & . & . & • & $\cdot$ & · & . & $\cdot$ & . & $\cdot$ & . & . & $\cdot$ & . \\
\hline & & 5 & . & . & . & . & . & . & . & . & $\cdot$ & $\cdot$ & $\cdot$ & $\cdot$ & $\cdot$ & $\cdot$ & $\cdot$ & $\cdot$ & $\cdot$ & $\cdot$ \\
\hline & & 10 & . & . & - & . & . & . & . & . & . & . & . & . & $\cdot$ & . & . & - & . & . \\
\hline
\end{tabular}




\section{SAMPling Distributions OF DEgREE OF DOMINANGE ESTIMATES}

The means of 500 estimates are given in table 7 for selected combinations of $p, r$ and $n$, and with $F=0$. In many cases one or more of the estimates was extremely large due to the denominator approximating zero, and in such cases the mean value is of little consequence and has been omitted from the table.

When the population value of $d$ is zero (populations 1 and 3 ) the estimate shows a bias which is small and positive for small $p$ but which rapidly

\section{TABLE 7}

Mean of sampling distribution of degree of dominance

\begin{tabular}{|c|c|c|c|c|c|c|c|c|c|c|c|}
\hline \multirow[b]{2}{*}{ Population } & \multirow[b]{2}{*}{$r$} & \multirow[b]{2}{*}{$n$} & \multicolumn{9}{|c|}{ Number of parents $(p)$} \\
\hline & & & 4 & 6 & 8 & 10 & 12 & 14 & 16 & 18 & 20 \\
\hline \multirow[t]{2}{*}{1} & 2 & $\begin{array}{r}2 \\
10\end{array}$ & - & $=$ & $-\overline{0.01}$ & $\overline{0.04}$ & $\overline{0.03}$ & $\overline{0.01}$ & $\begin{array}{l}0.24 \\
0.01\end{array}$ & $\begin{array}{r}0.04 \\
-0.01\end{array}$ & $\begin{array}{l}0.06 \\
0.00\end{array}$ \\
\hline & 5 & $\begin{array}{r}2 \\
10\end{array}$ & 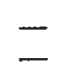 & $-\overline{0.07}$ & $\overline{0.09}$ & $\overline{0.00}$ & $\begin{array}{l}0.12 \\
0.01\end{array}$ & $\begin{array}{l}0.03 \\
0.00\end{array}$ & $\begin{array}{l}0.03 \\
0.00\end{array}$ & $\begin{array}{l}0.00 \\
0.00\end{array}$ & $\begin{array}{l}0.01 \\
0.00\end{array}$ \\
\hline \multirow[t]{2}{*}{2} & 2 & $\begin{array}{r}2 \\
10\end{array}$ & - & - & - & - & $\overline{1 \cdot 43}$ & $\begin{array}{l}1.36 \\
1 \cdot 28\end{array}$ & $\begin{array}{l}1 \cdot 78 \\
1 \cdot 24\end{array}$ & $\begin{array}{l}1.46 \\
1.20\end{array}$ & $\begin{array}{l}1 \cdot 40 \\
1 \cdot 16\end{array}$ \\
\hline & 5 & $\begin{array}{r}2 \\
10\end{array}$ & - & - & - & $\overline{1.48}$ & $\begin{array}{l}1.99 \\
1.33\end{array}$ & $\begin{array}{l}1.41 \\
1.25\end{array}$ & $\begin{array}{l}1.30 \\
1.21\end{array}$ & $\begin{array}{l}1.24 \\
1 \cdot 18\end{array}$ & $\begin{array}{l}1.19 \\
1 \cdot 15\end{array}$ \\
\hline \multirow[t]{2}{*}{3} & 2 & $\begin{array}{r}2 \\
10\end{array}$ & - & $\overline{0.03}$ & $\overline{0.03}$ & $\begin{array}{l}0 \cdot 10 \\
0.00\end{array}$ & $\begin{array}{l}0.05 \\
0.00\end{array}$ & $\begin{array}{r}-0.01 \\
0.00\end{array}$ & $\begin{array}{l}0.02 \\
0.00\end{array}$ & $\begin{array}{r}-0.01 \\
0.00\end{array}$ & $\begin{array}{l}0.00 \\
0 \cdot 00\end{array}$ \\
\hline & 5 & $\begin{array}{r}2 \\
10\end{array}$ & $\overline{0.00}$ & $\begin{array}{r}0.28 \\
-0.01\end{array}$ & $\overline{0.01}$ & $\begin{array}{l}0.01 \\
0.00\end{array}$ & $\begin{array}{l}0.01 \\
0.00\end{array}$ & $\begin{array}{l}0.00 \\
0.00\end{array}$ & $\begin{array}{l}0.00 \\
0.00\end{array}$ & $\begin{array}{l}0.00 \\
0.00\end{array}$ & $\begin{array}{l}0.00 \\
0.00\end{array}$ \\
\hline \multirow[t]{2}{*}{4} & 2 & $\begin{array}{r}2 \\
10\end{array}$ & - & - & $\overline{1.62}$ & $\begin{array}{l}1.74 \\
1.44\end{array}$ & $\begin{array}{l}1.48 \\
1.31\end{array}$ & $\begin{array}{l}1.29 \\
1.24\end{array}$ & $\begin{array}{l}1.25 \\
1.20\end{array}$ & $\begin{array}{l}1.20 \\
1.18\end{array}$ & $\begin{array}{l}1 \cdot 16 \\
1 \cdot 15\end{array}$ \\
\hline & 5 & $\begin{array}{r}2 \\
10\end{array}$ & 二 & - & $\begin{array}{l}1.46 \\
1.42\end{array}$ & $\begin{array}{l}1.51 \\
1.40\end{array}$ & $\begin{array}{l}1.34 \\
1.30\end{array}$ & $\begin{array}{l}1.26 \\
1.24\end{array}$ & $\begin{array}{l}1.21 \\
1.19\end{array}$ & $\begin{array}{l}1 \cdot 19 \\
1 \cdot 18\end{array}$ & $\begin{array}{l}1 \cdot 15 \\
1 \cdot 14\end{array}$ \\
\hline
\end{tabular}

decreases as the number of parents is increased. However, there is a marked positive bias for populations 2 and 4, ranging from approximately 50 per cent. of the true value when $p=10$ through to 20 per cent. when $p=20$. There is a tendency for the bias to decrease with increasing $r$ and $n$. The results for $F=1$ closely follow those for $F=0$ and will not be presented.

The statistic $i$ was again used as a measure of the efficiency of estimation and the values for populations 1 and 2 are presented in tables $8 a$ and $8 b$ respectively. The absence of a value indicates that the sampling variance was greater than 100 , and from the pattern of these omissions it is concluded that values of $p$ less than 10 are generally unsatisfactory. The level of inbreeding has a marked effect on $i$ for population $l$ but there is no tendency for $i$ to attain a local maximum, at least for the range of values of $p, r$ and $n$ which were tested. By contrast, for the second population there is an effect of $F$ only at the lower levels of $r$ and $n$, and $i$ is generally greatest for small $r$. As $n$ increases, a maximum for $i$ becomes evident at $p=16$.

It is believed that nothing would be gained from the presentation in 
detail of the results for the remaining two populations. The magnitude of $i$ is generally five to ten times greater for population 3 than for population 1 but there is again no tendency for a maximum value to be attained. For population 4 the value of $i$ is up to three times greater than for population 2 and the results concur in showing a region of maximisation around $p=16$.

TABLE $8 a$

Degree of dominance; amount of information per individual $\left(\times 10^{3}\right)$ for population 1

\begin{tabular}{|c|c|c|c|c|c|c|c|c|c|c|}
\hline \multirow[b]{2}{*}{$r$} & & \multicolumn{9}{|c|}{ Number of parents $(p)$} \\
\hline & $n$ & 4 & 6 & 8 & 10 & 12 & 14 & 16 & 18 & 20 \\
\hline \multicolumn{11}{|c|}{$F=0$} \\
\hline \multirow[t]{4}{*}{2} & 2 & - & - & 一 & - & - & - & 0 & 0 & 0 \\
\hline & 3 & - & - & - & - & 0 & 0 & 0 & 1 & 1 \\
\hline & 5 & - & - & - & - & 0 & 1 & 1 & 1 & 1 \\
\hline & 10 & - & 一 & 0 & 1 & 2 & 2 & 2 & 3 & 3 \\
\hline \multirow[t]{4}{*}{3} & 2 & - & - & - & - & 0 & 0 & 1 & 1 & 1 \\
\hline & 3 & - & - & - & 一 & 0 & 1 & 1 & 1 & 1 \\
\hline & 5 & - & - & 0 & 1 & 1 & 2 & 2 & 2 & 3 \\
\hline & 10 & - & - & 0 & 2 & 3 & 4 & 4 & 5 & 6 \\
\hline \multirow[t]{4}{*}{5} & 2 & - & - & - & - & 0 & 1 & 1 & 2 & 2 \\
\hline & 3 & - & - & 0 & 1 & 1 & 2 & 2 & 3 & 3 \\
\hline & 5 & - & - & 1 & 2 & 3 & 3 & 4 & 5 & 5 \\
\hline & 10 & - & 0 & 0 & 5 & 6 & 7 & 8 & 9 & 11 \\
\hline \multicolumn{11}{|c|}{$F=1$} \\
\hline \multirow[t]{4}{*}{2} & 2 & - & 0 & 0 & 0 & 2 & 6 & 8 & 10 & 11 \\
\hline & 3 & 一 & 0 & 0 & 0 & 8 & 11 & 13 & 16 & 17 \\
\hline & 5 & - & - & 5 & 12 & 17 & 20 & 22 & 28 & 30 \\
\hline & 10 & 0 & 1 & 1 & 29 & 38 & 42 & 46 & 57 & 61 \\
\hline \multirow[t]{4}{*}{3} & 2 & - & 0 & 0 & 0 & 9 & 13 & 16 & 19 & 21 \\
\hline & 3 & - & 0 & 1 & 11 & 17 & 21 & 25 & 30 & 33 \\
\hline & 5 & - & 0 & 2 & 24 & 32 & 38 & 43 & 51 & 56 \\
\hline & 10 & 1 & 0 & 15 & 55 & 68 & 78 & 88 & 103 & 114 \\
\hline \multirow[t]{4}{*}{5} & 2 & 一 & - & 4 & 15 & 20 & 27 & 32 & 36 & 41 \\
\hline & 3 & - & 0 & 2 & 27 & 34 & 42 & 49 & 56 & 63 \\
\hline & 5 & - & 1 & 8 & 49 & 61 & 73 & 84 & 94 & 107 \\
\hline & 10 & - & - & 46 & 106 & 127 & 149 & 170 & 191 & 216 \\
\hline
\end{tabular}

\section{Discussion}

A number of different heritability estimates may be obtained for a population depending on the types of selection which are envisaged, and only two of these have been considered. The method of estimation in which each individual of the sample is scored may also be modified, for example by recording only the means of full-sib families and analysing these data. For these reasons the conclusions of the present study can only be stated in very broad terms if they are to have any relevance to the estimation of heritability in general. 
First, an estimate may be decidedly biassed if there are fewer than 8 parents and this places one restriction on the number of parents to be used. The problem would not exist if a correction could be made for the bias, but it has not been possible to derive the necessary function.

TABLE $8 b$

Degree of dominance; amount of information per individual $\left(\times 10^{5}\right)$ for population 2

\begin{tabular}{|c|c|c|c|c|c|c|c|c|c|c|}
\hline \multirow[b]{2}{*}{$r$} & \multirow[b]{2}{*}{$n$} & \multicolumn{9}{|c|}{ Number of parents $(p)$} \\
\hline & & 4 & 6 & 8 & 10 & 12 & 14 & 16 & 18 & 20 \\
\hline \multicolumn{11}{|c|}{$F=0$} \\
\hline \multirow[t]{4}{*}{2} & 2 & - & - & - & - & 一 & 3 & 11 & 19 & 10 \\
\hline & 3 & - & - & - & - & $\ldots$ & 6 & 28 & 38 & 37 \\
\hline & 5 & - & - & - & - & 2 & 31 & 46 & 55 & 56 \\
\hline & 10 & - & - & - & - & 29 & 46 & 57 & 59 & 59 \\
\hline \multirow[t]{4}{*}{3} & 2 & - & - & - & - & - & 7 & 32 & 40 & 40 \\
\hline & 3 & - & - & - & - & - & 28 & 48 & 55 & 57 \\
\hline & 5 & - & - & - & 4 & 22 & 45 & 59 & 63 & 64 \\
\hline & 10 & - & 一 & 4 & 11 & 33 & 46 & 54 & 51 & 52 \\
\hline \multirow[t]{5}{*}{5} & 2 & - & - & 一 & - & 2 & 34 & 55 & 59 & 62 \\
\hline & 3 & - & - & - & 4 & $2 \overline{2}$ & 46 & 62 & 63 & 66 \\
\hline & 5 & - & - & - & 5 & 33 & 49 & 59 & 56 & 57 \\
\hline & 10 & - & - & - & 17 & 30 & 37 & 42 & 37 & 37 \\
\hline & \multicolumn{10}{|c|}{$F=1$} \\
\hline \multirow[t]{4}{*}{2} & 2 & - & - & - & 6 & 22 & 91 & 184 & 201 & 202 \\
\hline & 3 & - & - & - & 5 & 19 & 125 & 187 & 189 & 191 \\
\hline & 5 & - & - & - & 9 & 62 & 120 & 156 & 147 & 148 \\
\hline & 10 & - & - & - & - & 56 & 83 & 99 & 88 & 89 \\
\hline \multirow[t]{4}{*}{3} & 2 & - & - & - & 5 & 19 & 127 & 193 & 190 & 194 \\
\hline & 3 & - & - & - & 3 & 58 & 125 & 168 & 157 & 159 \\
\hline & 5 & - & - & - & 10 & 63 & 100 & 123 & 111 & 112 \\
\hline & 10 & - & - & - & 3 & 44 & 61 & 71 & 62 & 62 \\
\hline \multirow[t]{4}{*}{5} & 2 & - & - & - & 9 & 63 & 121 & 160 & 147 & 150 \\
\hline & 3 & - & - & - & 10 & 64 & 100 & 124 & 110 & 112 \\
\hline & 5 & - & - & - & 1 & 50 & 70 & 83 & 73 & 73 \\
\hline & 10 & - & - & - & 6 & 30 & 39 & 45 & 39 & 39 \\
\hline
\end{tabular}

With regard to the amount of information per individual it was found for both $h_{\text {individual }}^{2}$ and $h_{\text {family }}^{2}$ that a diallel analysis with 8 to 10 parents is optimal. There should be few replicates and the number of individuals per cross should also be small, but it is at this point that some account must be taken of practical issues. A common practice with plants is to surround each plot with border material, and if there are only 2 or 3 plants per plot then the ratio of border to experimental material is too great. An $n$ of 10 or 20 is more realistic even though this will inevitably lead to a loss of efficiency.

To counter any possible misunderstanding, it is not proposed that an estimate should necessarily be obtained from a single diallel analysis with 8 
parents, 2 replicates and 20 individuals per cross. Instead, the suggested procedure is to specify the total number of individuals to be grown and then to carry out as many 8-parent diallels as are consistent with this limitation on total number. There is the implicit assumption that the total size of the experiment is determined by restrictions of time or space rather than by the magnitudes of the sampling variances of estimates. However, table 9 has

TABLE 9

Number of 8-parent diallels (a), and number of parents in a single diallel (b) necessary to produce $\mathrm{t}=4$ (see text) for $h_{\mathrm{1ndividual}}^{2}$ with 20 individuals per family; the total number of individuals in each analysis is shown in brackets

\begin{tabular}{cccccc}
\multirow{2}{*}{$\begin{array}{c}\text { Population } \\
1\end{array}$} & $r$ & $\overbrace{(a)} F=0$ & \multicolumn{2}{c}{$F=1$} \\
& 2 & $5(2800)$ & $28(6560)$ & $4(2240)$ & $22(4620)$ \\
& 3 & $5(2800)$ & $28(6560)$ & $4(2240)$ & $22(4620)$ \\
2 & 2 & $6(3360)$ & $29(8120)$ & $5(2800)$ & $24(4520)$ \\
& 3 & $5(2800)$ & $29(8120)$ & $5(2800)$ & $24(4520)$ \\
3 & 2 & $3(1680)$ & $17(2720)$ & - & $7(420)$ \\
& 3 & $3(1680)$ & $17(2720)$ & - & $7(420)$ \\
4 & 2 & $3(1680)$ & $18(3060)$ & $2(1120)$ & $9(720)$ \\
& 3 & $3(1680)$ & $18(3060)$ & $2(1120)$ & $9(720)$
\end{tabular}

been prepared as a guide to the precision of estimates. The variable $t$ is defined as

$$
t=\frac{\text { mean of sampling distribution }}{\text { standard deviation of sampling distribution }},
$$

and the table shows the number of 8-parent diallels necessary to produce $t=4$ when there are 20 individuals per family. Also shown in each case is the number of parents necessary to achieve the same result from a single diallel. The expression ( 1 ) was used for $p$ greater than 20 since it was found to be accurate in this region, and the other values were obtained from the simulation results with interpolation if necessary. The total number of individuals for each experimental design is shown in brackets and on this basis the "multiple diallel " procedure is generally twice as efficient as the use of a single diallel.

The results for degree of dominance are not as easily generalised. The estimator is virtually unbiassed when the population value is zero but may be considerably biassed in other cases, both for inbred and non-inbred parents. However, when the population value is zero the amount of information per individual reaches no local maximum but is an increasing function of $p, r$ and $n$. This can be shown from (1) since if $X$ has an expected value of zero then

so that

$$
\operatorname{var}(X / Y)=\operatorname{var}(X) / \Upsilon^{2}
$$




$$
\begin{aligned}
& \operatorname{var}(\hat{d})= \operatorname{var}\left(2 \hat{\sigma}_{D}^{2}\right) /\left(\sigma_{A}^{2}\right)^{2} \\
&=\frac{64}{n^{2} r^{2}(1+F)^{4} \sigma_{A}^{4}}[\operatorname{var} \text { (s.c.a. mean square) } \\
&\quad+\operatorname{var} \text { (exp. error mean square) }] \\
&=\frac{64}{n^{2} r^{2}(1+F)^{4} \sigma_{A}^{4}}\left[\begin{array}{c}
\frac{2 \text { (s.c.a. mean square })^{2}}{\frac{1}{2} p(p-3)} \\
\left.\quad+\frac{2(\text { exp. error mean square })^{2}}{\frac{1}{2}(r-1)(p-2)(p+1)}\right] .
\end{array}\right.
\end{aligned}
$$

Thus the variance is inversely related to $p, r, n$ and $F$, and the amount of information per individual therefore increases with each of these variables. In particular, an increase of $F$ from 0 to 1 gives about a 16 -fold increase in the relative amount of information and this may be a means of improving efficiency if the value of $d$ is expected to be small. When $d$ approximates unity, the effect of $F$ is not as great.

In summary, when $d$ is close to zero there is very little bias in the mean but efficiency demands large values for $p, r$ and $n$. As $d$ increases so does the bias, but values of $p$ around 16 are preferred on the grounds of efficiency along with small $r$ and large $n$. However, if both the heritability and the degree of dominance are to be estimated it is the former parameter which is of greater practical use, so it would seem that the number of parents should be set at around 10 and allowance made for any bias in the degree of dominance estimate.

The bias in $\hat{d}^{\frac{1}{2}}$, which is more commonly estimated, is expected to be approximately one-half that of $\hat{d}$. Further, it is probably reasonable to assume that the conclusions on efficiency of estimation apply equally as well to $\hat{d}^{\frac{1}{2}}$ as they do to $\hat{d}$.

\section{Summary}

1. A study is made of the estimation of genetic parameters using the diallel cross in which parents and reciprocal hybrids are not included in the evaluation procedure. The parameters considered are the heritability of individuals $\left(h_{\text {individual }}^{2}\right)$, the heritability of full-sib families $\left(h_{\text {family }}^{2}\right)$, and the degree of dominance.

2. The number of parents, the number of replicates, and the number of individuals per cross are each given a range of values, and for each combination the sampling distributions of the three parameters are determined by a simulation procedure which involves the generation of random chi-square values.

3. The amount of information on a parameter is defined as the inverse of the sampling variance, and the most efficient design for each parameter is defined as that which results in a relatively unbiassed estimator and which maximises the amount of information per individual evaluated.

4. For both $h_{\text {individual }}^{2}$ and $h_{\text {family }}^{2}$ the general conclusion is that from 8 to 10 parents are preferred, with few individuals per cross and only two or three replicates. If there are fewer than 8 parents the estimator may be appreciably biassed. It is suggested that as many 8- or 10-parent diallels should be carried out as are consistent with the time and space available. 
5. The conclusions are less general for the degree of dominance. When the population value is close to zero there is no apparent method of minimising the sampling variance except by increasing one or all of the controllable variables. The bias in the estimator, however, is small.

6. For other population values the bias may be greater but the preferred number of parents, on the grounds of efficiency, is approximately 16.

\section{REFERENCES}

cockerham, c. c. 1963. Estimation of genetic variances. In Statistical Genetics and Plant Breeding: NAS-NRG, 982, 53-94.

COMSTOCK, R. E., AND ROBINSON, H. F. 1948. The components of genetic variance in populations of biparental progenies and their use in estimating the average degree of dominance. Biometrics, 4, 254-266.

GRIFFING, B. 1956. Concept of general and specific combining ability in relation to diallel crossing systems. Aust. 7. Biol. Sci., 9, 463-493.

hayman, B. r. 1960. The theory and analysis of diallel crosses III. Genetics, 45, 155-172. KEMPthorne, O., AND GURNow, R. N. 1961. The partial diallel cross. Biometrics, 17, 229 250.

PEARSON, K. 1930. Tables for Statisticians and Biometricians, Part 1 (3rd ed.). Cambridge Univ. Press, England.

SMITH, h. FAIRFIELD. 1938. An empirical law describing heterogeneity in the yields of agricultural crops. F. Agric. Sci., 28, 1-23. 